\title{
Records of two gonad-infecting species of Philometra (Nematoda: Philometridae) from marine fishes off Iraq, including the description of Philometra parabrevicollis n. sp. from the bigeye snapper Lutjanus lutjanus Bloch (Pisces, Lutjanidae)
}

\author{
František Moravec $(\mathbb{D}) \cdot$ Jawad A. Mizher $\cdot$ Atheer H. Ali
}

Received: 26 March 2021 / Accepted: 28 May 2021/Published online: 12 June 2021

(C) The Author(s), under exclusive licence to Springer Nature B.V. 2021

\begin{abstract}
Recent examinations of some marine fishes from off the southern coast of Iraq revealed the presence of two species of Philometra Costa, 1845 (Nematoda: Philometridae): P. parabrevicollis $\mathbf{n}$. sp. (males and subgravid and nongravid females) from the ovary of the bigeye snapper Lutjanus lutjanus Bloch (Perciformes, Lutjanidae) and Philometra sp. (subgravid females) from the ovary of the bartail flathead Platycephalus indicus (Linnaeus) (Perciformes, Platycephalidae). Specimens of species are described and illustrated based on light and scanning electron microscopical examinations. Philometra parabrevicollis $\mathbf{n}$. sp. is mainly characterised by the length of spicules $(267-285 \mu \mathrm{m})$ and gubernaculum (159-168 $\mu \mathrm{m})$, the gubernaculum/spicule length ratio (1:1.64-1.76), the structure of the gubernaculum distal
\end{abstract}

This article was registered in the Official Register of Zoological Nomenclature (ZooBank) as: urn:lsid:zoobank.org:pub: B1BE8C8E-AF9D-4606-947C-41581E76AB90. This article was published as an Online First article on the online publication date shown on this paper. The article should be cited by using the doi number. This is the Version of Record.

F. Moravec $(\bowtie)$

Institute of Parasitology, Biology Centre of the Czech

Academy of Sciences, Branišovská 31,

37005 České Budějovice, Czech Republic

e-mail: moravec@paru.cas.cz

J. A. Mizher - A. H. Ali

Department of Fisheries and Marine Resources, College

of Agriculture, University of Basrah, Basrah, Iraq tip and of the male caudal end, and the body length of males $(4.03-4.90 \mathrm{~mm})$. The description of this new species again confirms a high degree of host specificity of gonad-infecting species of Philometra in congeneric lutjanid hosts. Although Philometra sp. parasitising $P$. indicus in Iraqi waters was previously recorded, its subgravid females are described for the first time. A key to gonad-infecting species of Philometra parasitic in fishes of the family Lutjanidae is provided.

\section{Introduction}

The dracunculoid family Philometridae Baylis \& Daubney, 1926 contains many species of nematode parasites of fishes. Of the 17 presently recognised philometrid genera (Moravec \& Shamsi, 2017; Moravec et al., 2019), the great majority of described species belongs to Philometra Costa, 1845, that includes parasites of the body cavity and various body tissues of freshwater, brackish-water and marine fishes (Ivashkin et al., 1971; Moravec, 2006; Anderson et al., 2009; Moravec \& de Buron, 2013). To date, 13 philometrid species of the genera Clavinemoides Moravec, Khosheghbal \& Pazooki, 2013, Philometra and Philometroides Yamaguti, 1935 were recorded from marine fishes in the Arabian (= Persian) Gulf (Parukhin, 1976; Moravec \& Ali, 2005, 2013, 2014; Moravec et al., 2012, 2013, 2016a; Khosheghbal et al., 
2017); reports of two additional species, Philometra globiceps (Rudolphi, 1819) and P. lateolabracis (Yamaguti, 1935), in this region by Petter \& Sey (1997) and Kardousha (1999), respectively, were based on misidentifications (Moravec \& Ali, 2013). Also the finding of Philometra madai Quiazon, Yoshinaga \& Ogawa, 2008, a specific parasite of the Sparidae in Japan (see Quiazon et al., 2008; Moravec et al., 2019), in Lutjanus monostigma (Cuvier) (Lutjanidae) in the Red Sea, off Saudi Arabia (Al-Jahdali, 2014) is evidently based on misidentification, because only unidentifiable nematode females were collected; these should be reported as Philometra sp. until conspecific males are obtained. Records of unidentified species of Philometra from different fish hosts reported by Parukhin (1976), El-Naffar et al. (1992), Mohamed et al. (2010), Hosseini et al. (2013), Ali et al. (2014) and Moravec et al. (2016a) indicate the presence of additional, not yet established philometrid species in marine fishes of the Arabian Gulf.

During recent helminthological investigations of some marine fishes in the Arabian Gulf, off the coast near Basrah, southern Iraq, specimens of Philometra were found in the ovaries of the bigeye snapper Lutjanus lutjanus Bloch (Perciformes, Lutjanidae) and the bartail flathead Platycephalus indicus (Linnaeus) (Perciformes, Platycephalidae). Results of their closer examination are described below.

Lutjanus lutjanus (maximum body length $35 \mathrm{~cm}$ ) is a tropical marine, highly commercial fish, whereas $P$. indicus (maximum body length $100 \mathrm{~cm}$ ) is a subtropical marine commercial fish and gamefish; both of them have an Indo-West Pacific distribution (Froese \& Pauly, 2021).

\section{Materials and methods}

Fishes were caught using trawl and drift gill nets during October-December 2019 and January-May and August-September 2020. The nematodes obtained from fresh fishes were washed in physiological saline and fixed in hot $5 \%$ formalin. For light microscopy examination, the nematodes were cleared with glycerine. Drawings were made with the aid of a Zeiss drawing attachment. Specimens used for scanning electron microscopy (SEM) were postfixed in $1 \%$ osmium tetroxide (in phosphate buffer), dehydrated through a graded acetone series, critical-point-dried and sputter-coated with gold; they were examined using a JEOL JSM-7401F scanning electron microscope at an accelerating voltage of $4 \mathrm{kV}$ (GB low mode). All measurements are in micrometres unless otherwise indicated. The fish nomenclature adopted follows Eschmeyer's Catalog of Fishes (Van der Laan et al., 2021). Ecological terms (prevalence and intensity of infection) are used in accordance with Bush et al. (1997).

\section{Philometridae Baylis \& Daubney, 1926 Philometra Costa, 1845}

Type species: Philometra reticulatum Costa, 1845, by original designation [= syn. of Philometra globiceps (Rudolphi, 1816) Railliet, 1916]

\section{Philometra parabrevicollis $\mathrm{n} . \mathrm{sp}$}

Type-host: Lutjanus lutjanus Bloch (Perciformes: Lutjanidae), bigeye snapper.

Type-locality: Near Basrah, northwestern Arabian Gulf, Iraq (collected in May 2020).

Type-material: Male holotype, female allotype and 17 paratypes (4 males, 13 females) in the Helminthological Collection of the Institute of Parasitology, BC CAS, České Budějovice, Czech Republic (Cat. No. N1255).

Prevalence and intensity: 5\% (3 fish infected/62 fish examined); 4-9 (mean 7) nematode specimens per fish.

Site in host: Ovary.

ZooBank registration: To comply with the regulations set out in article 8.5 of the amended 2012 version of the International Code of Zoological Nomenclature (ICZN, 2012), details of the new species have been submitted to ZooBank. The Life Science Identifier (LSID) for Philometra parabrevicollis n. sp. is urn:lsid:zoobank.org:act:9BB75C20-F52F-44AB-

ADEE-62E2CA9389FF.

Etymology: The species name parabrevicollis is a Latin adjective composed of two parts, par (= match, alike, comparable with) and brevicollis (= the name of nematode species), and relates to the fact that this nematode is morphologically very similar to Philometra brevicollis. 


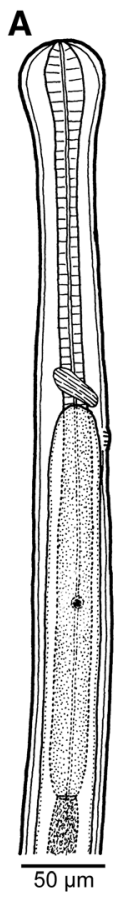

B
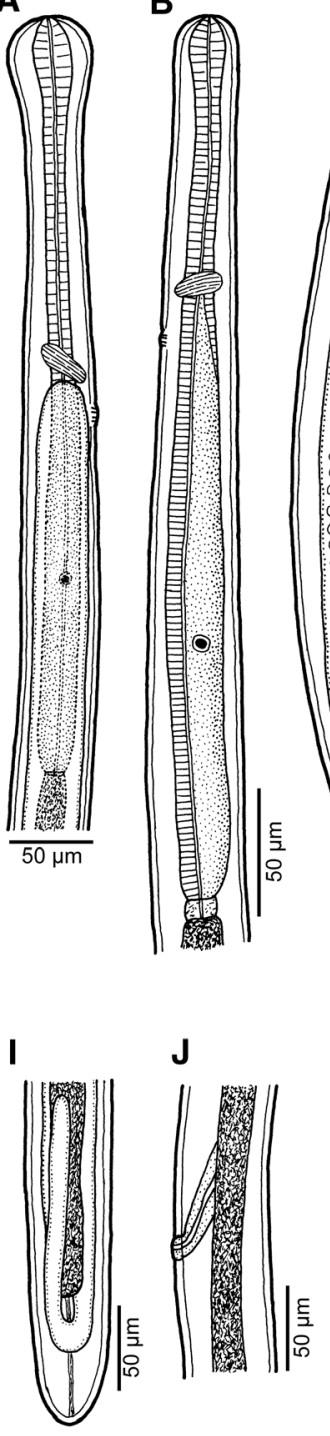

C

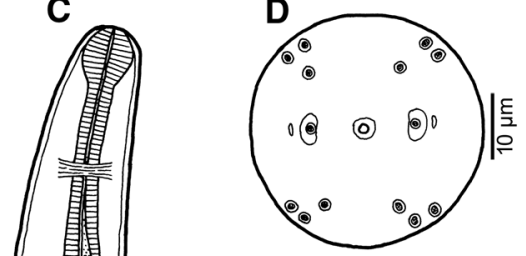

G

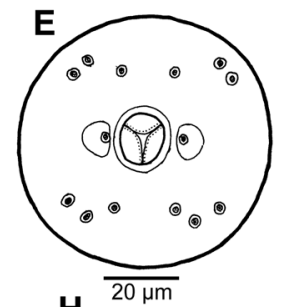

H

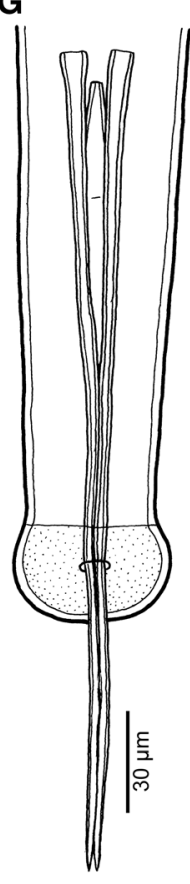

M
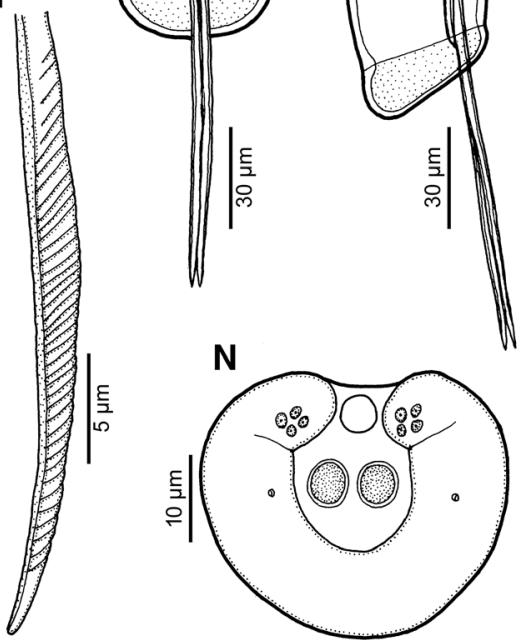

Fig. 1 Philometra parabrevicollis $\mathbf{n}$. sp. from Lutjanus lutjanus. A, B, Anterior end of male and nongravid female, respectively, lateral views; C, Anterior end of subgravid female, lateral view; D, E, Cephalic end of male and subgravid female, respectively, apical views; F, Posterior end of subgravid female, dorsoventral view; G, H, Posterior end of male, ventral and lateral views, respectively; I, J, Posterior end and vulva of nongravid female, lateral views, respectively; K, Gubernaculum, lateral view; L, M, Distal end of gubernaculum, dorsal and lateral views, respectively; N, Caudal end of male, apical view

\section{Description}

Male [Based on 8 specimens; measurements of holotype in parentheses; Figs. 1A, D, G, H, K-N, 2C-G, 3A-G] Body filiform, whitish, 4.03-4.90 (4.90) mm long, maximum width 60-84 (66); anterior end of body rounded, 45-54 (48) wide, with conspicuous constriction at short distance posterior to cephalic extremity (Figs. 1A, 2E); width of body at this constriction 33-39 (36). Maximum width/body length ratio 1:53-74 (1:74). Cuticle smooth. Oral aperture small, circular. Cephalic papillae 14 in number, arranged in 2 circles; outer circle formed by 4 submedian pairs, inner circle consists of 4 submedian 

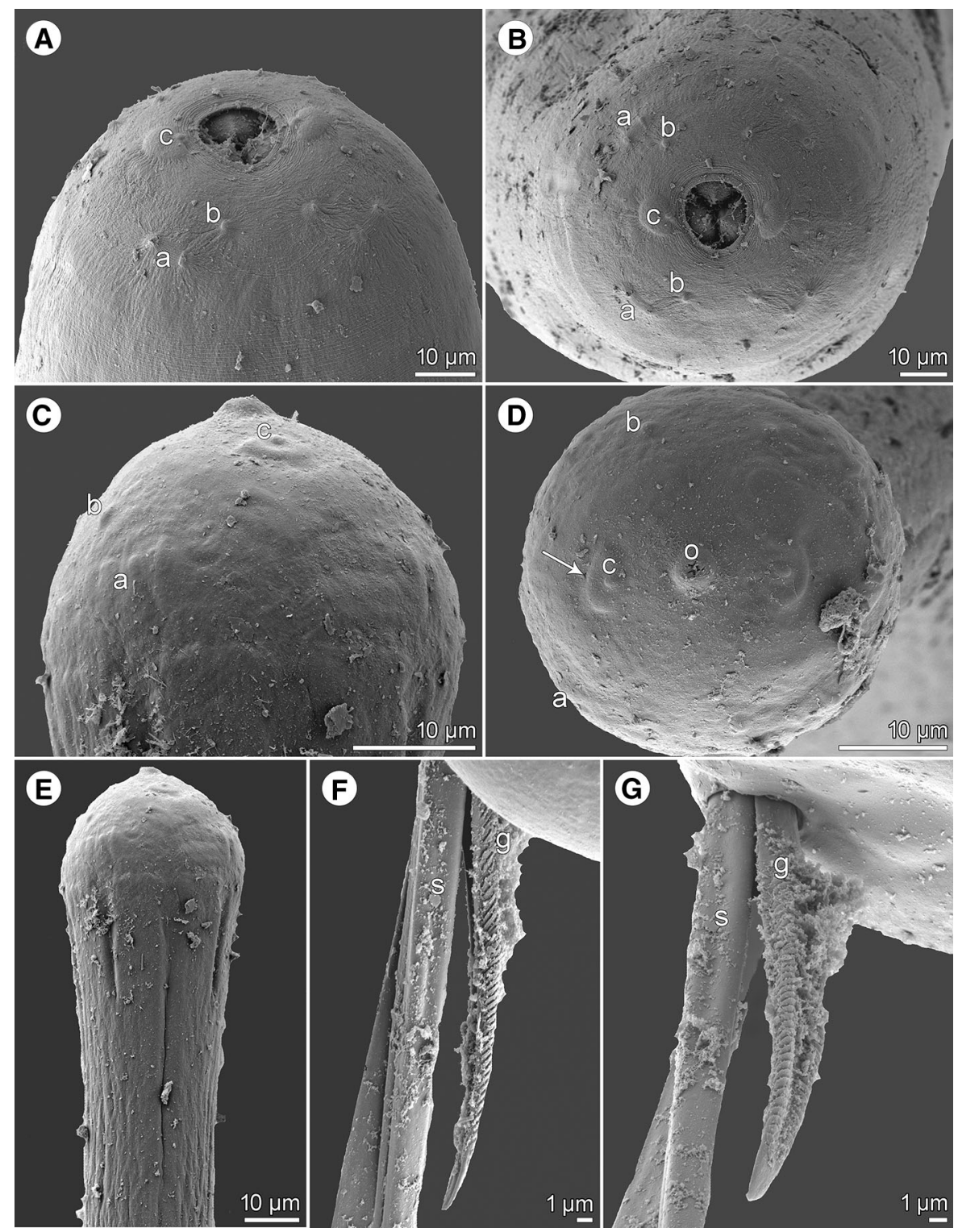

Fig. 2 Philometra parabrevicollis n. sp. from Lutjanus lutjanus, scanning electron micrographs. A, B, Cephalic end of subgravid female, subventral and apical views, respectively; C, D, Cephalic end of male, lateral and apical views, respectively (arrow indicates amphid); E, Anterior body end of male, lateral view; F, G, Distal end of gubernaculum, lateral and subdorsal views, respectively. Abbreviations: a, submedian pair of outer cephalic papillae; b, inner submedian cephalic papilla; c, inner lateral cephalic papilla; g, gubernaculum; o, oral aperture; s, spicule

and 2 lateral papillae (Figs. 1D, 2C, D). Pair of small, slit-like lateral amphids somewhat posterior to lateral cephalic papillae (Figs. 1D, 2D). Oesophagus 462-594 (525) long, comprising 10-12\% (11\%) of body length, with slight inflation at anterior end measuring 36-51 × 24-33 $(39 \times 30)$; posterior part of muscular oesophagus overlapped by well-developed oesophageal gland with large cell nucleus; maximum width of gland 24-30 (27). Ventriculus indistinct. Nerve-ring and oesophageal nucleus 183-228 and 309-426, respectively, from anterior extremity. Excretory pore 204-225 (255) from anterior end. Testis extending anteriorly approximately to level just posterior to nerve ring (Fig. 1A). Posterior end of body blunt, 36-45 (42) wide, provided with broad U-shaped mound situated laterally and dorsally to cloacal 


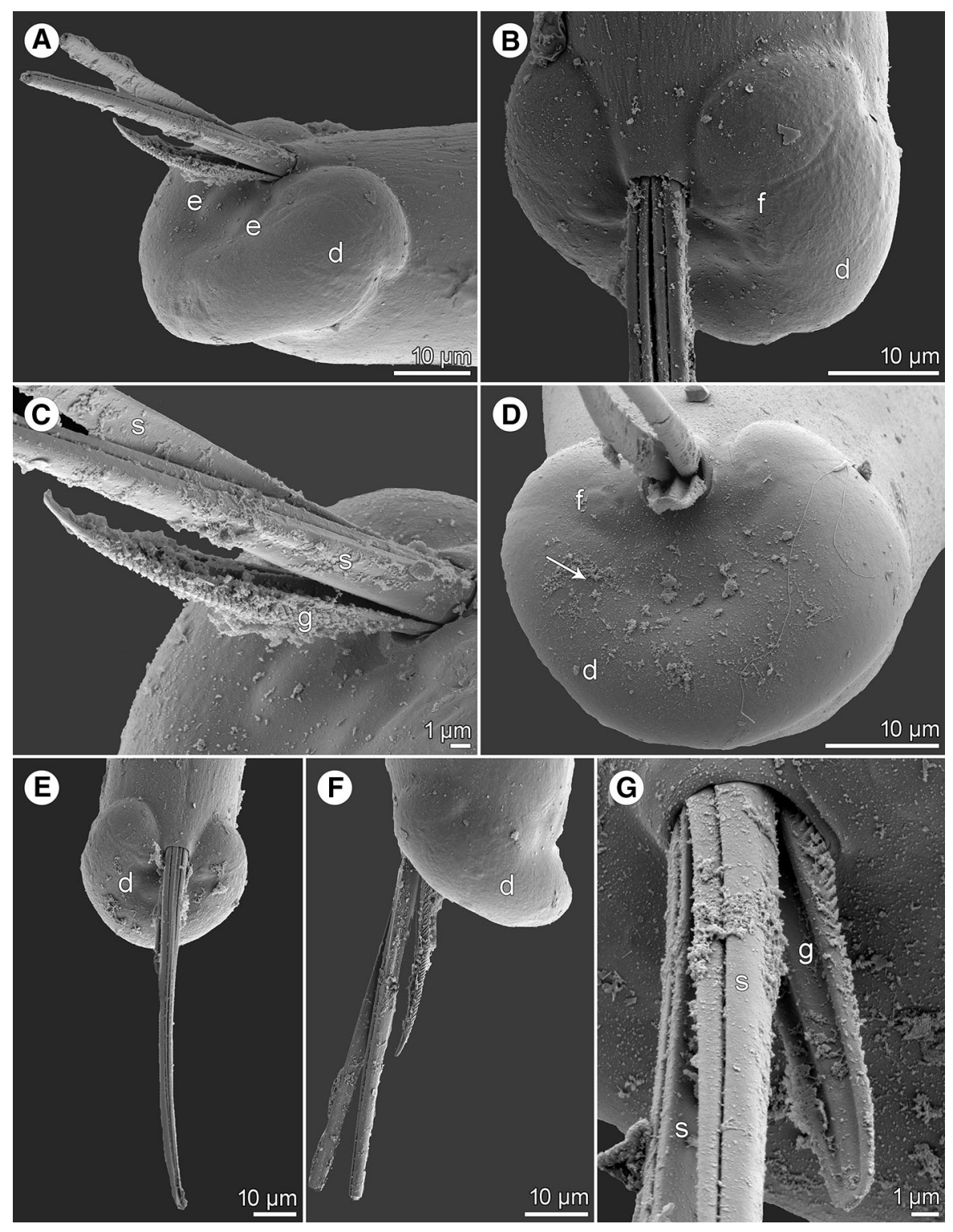

Fig. 3 Philometra parabrevicollis n. sp. from Lutjanus lutjanus, scanning electron micrographs of male. A, B, Caudal end, sublateral and subventral views, respectively; C, Region of cloaca, ventrolateral view; D, Caudal end, apical view (arrow indicates phasmid); E, F, Posterior end of body, ventral and lateral views, respectively; G, Region of cloaca, subventral view. Abbreviations: d, caudal mound; e, postcloacal papilla-like protuberance; f, group of four adanal papillae; g, gubernaculum; s, spicule

opening (Figs. 1N, 3A, B, D-F). Four pairs of small, very flat, hardly visible adanal papillae present on caudal mound; 2 large papilla-like protuberances present posterior to cloacal aperture; pair of small sublateral phasmids present on caudal mound at level of postcloacal protuberances (Figs. 1N, 3A, B, D). Spicules needle-like, approximately equally long, with somewhat expanded proximal and sharply pointed distal tips (Figs. 1G, H, 2F, G, 3A-G); length of spicules 267-285 (285), representing 5.5-6.7\% $(5.8 \%)$ of body length. Gubernaculum narrow, 159-168 (162) long, with anterior portion somewhat dorsally bent (Fig. 1H, K); length of anterior bent part 33-48 (48), comprising 20-30\% (30\%) of entire gubernaculum length; distal portion of gubernaculum tongue-shaped in dorsal view, rounded at tip, each 
dorsolateral margin with rounded transversely striated ridge; these ridges separated along their entire length by smooth depressed distally tapering field (Figs. 1L, M, 2F, G, 3A, C, F); ventral surface of this region with 2 longitudinal grooves (Fig. 3C, D, G). Length ratio of gubernaculum and spicules 1:1.64-1.76 (1:1.76). Spicules and gubernaculum well sclerotised, yellowish, anterior part of gubernaculum and proximal ends of spicules colourless.

Subgravid female [Based on 4 ovigerous specimens; measurements of allotype in parentheses; Figs. 1C, F, E, 2A, B] Body whitish, 17.03-27.88 (27.45) $\mathrm{mm}$ long; maximum width/body length ratio 1:78-124 (1:96). Cephalic end rounded, 87-123 (105) wide. Cephalic papillae very small, indistinct in lateral view (Fig. 1C). Oral aperture oval, surrounded by 14 small cephalic papillae arranged in 2 circles: 4 submedian pairs of papillae of outer circle and 6 single papillae (4 submedian and 2 lateral) of inner circle; amphids indistinct (Figs. 1E, 2A, B). Oesophagus 789-884 (870) long including its anterior bulbous inflation, representing 3-5\% (3\%) of body length; anterior inflation 75-90 (75) long and 81-90 (90) wide; maximum width of posterior part of oesophagus including well-developed dorsal gland 51-81 (81) (Fig. 1C). Small ventriculus present, 21 (21) long, 60-66 (66) wide. Nerve-ring and oesophageal nucleus 218-245 (245) and 503-598 (598), respectively, from anterior extremity. Intestine straight, ending blindly; posterior end of intestine atrophied, forming ligament 180-270 (180) long attached ventrally to body wall close to posterior extremity (Fig. 1F). Vulva and anus absent. Ovaries reflexed near body ends. Uterus filled with eggs. Posterior end rounded, 69-150 (95) wide, with pair of minute papilla-like caudal projections (Fig. 1F).

Nongravid female [Based on 7 specimens; Fig. 1B, I, J] Body whitish, 5.56-9.27 mm long, maximum width 60-177; maximum width/body length ratio 1:52-93. Cephalic end rounded, 39-69 wide. Cephalic papillae small, indistinct in lateral view (Fig. 1B). Oesophagus including anterior bulbous inflation 540-857 long, comprising 9-12\% of body length; its anterior inflation 39-69 long and 27-66 wide. Posterior portion of oesophagus including oesophageal gland 30-54 wide (Fig. 1B). Nerve-ring and oesophageal nucleus 150-180 and 375-544, respectively, from anterior extremity. Ventriculus 6-24 long, 15-45 wide. Rudimentary vulva at $3.62-3.92 \mathrm{~mm}$ from anterior extremity (at 65-67\% of entire body end) in small specimens $5.56-5.83 \mathrm{~mm}$ long (Fig. $1 \mathrm{~J}$ ), but vulva absent in larger specimen $9.26 \mathrm{~mm}$ long. Uterus empty. Posterior end rounded, 36-163 wide, without caudal projections (Fig. 1I).

Remarks

Gonad-infecting species of Philometra are known to exhibit a high degree of host specificity (e.g., Moravec \& Manoharan, 2014a, b; Moravec et al., 2016b; Ghanmi et al., 2018; Moravec \& Barton, 2018). To date, the following ten species of Philometra parasitic in the gonads of Lutjanus spp. with known males have been described, all in the regions of the Atlantic Ocean (Gulf of Mexico), Indian Ocean (Bay of Bengal) and South Pacific Ocean (off Australia and New Caledonia) (Moravec \& Barton, 2018): P. arafurensis Moravec \& Barton, 2018, P. argentimaculati Moravec \& Manoharan, 2014, P. brevicollis Moravec \& Justine, 2011, P. carponotati Moravec \& Diggles, 2014, P. fulvi Moravec \& Manoharan, 2014, P. latispicula Moravec, Bakenhaster \& Fajer-Ávila, 2014, P. longispicula Moravec, Bakenhaster \& Fajer-Ávila, 2014, P. mawsonae Moravec \& Barton, 2018, P. mira Moravec \& Justine, 2011 and $P$. synagridis Moravec, Bakenhaster \& Fajer-Ávila, 2014 (see Moravec \& Justine, 2011; Moravec \& Diggles, 2014; Moravec \& Manoharan, 2014b; Moravec et al., 2014; Moravec \& Barton, 2018).

Of these, the spicules of six species are either distinctly shorter (P. fulvi, P. latispicula, P. mira and $P$. synagridis) or distinctly longer ( $P$. longispicula and $P$. mawsonae) than those in the new species. By the length of spicules, $P$. parabrevicollis $\mathbf{n}$. sp. somewhat resembles $P$. arafurensis, $P$. argentimaculati, $P$. brevicollis and $P$. carponotati. Males of all these four species, as well as that of the new species, are characterised by a distinct "neck" on their anterior body ends, by the presence of a U-shaped caudal mound and an elongate tongue-shaped distal portion of the gubernaculum with numerous dorsolateral transverse lamella-like structures with an elongate smooth dorsal field between them; a pair of small caudal papilla-like projections observed in the subgravid females were also found in gravid or subgravid females of $P$. arafurensis, $P$. brevicollis and P. carponotati. 

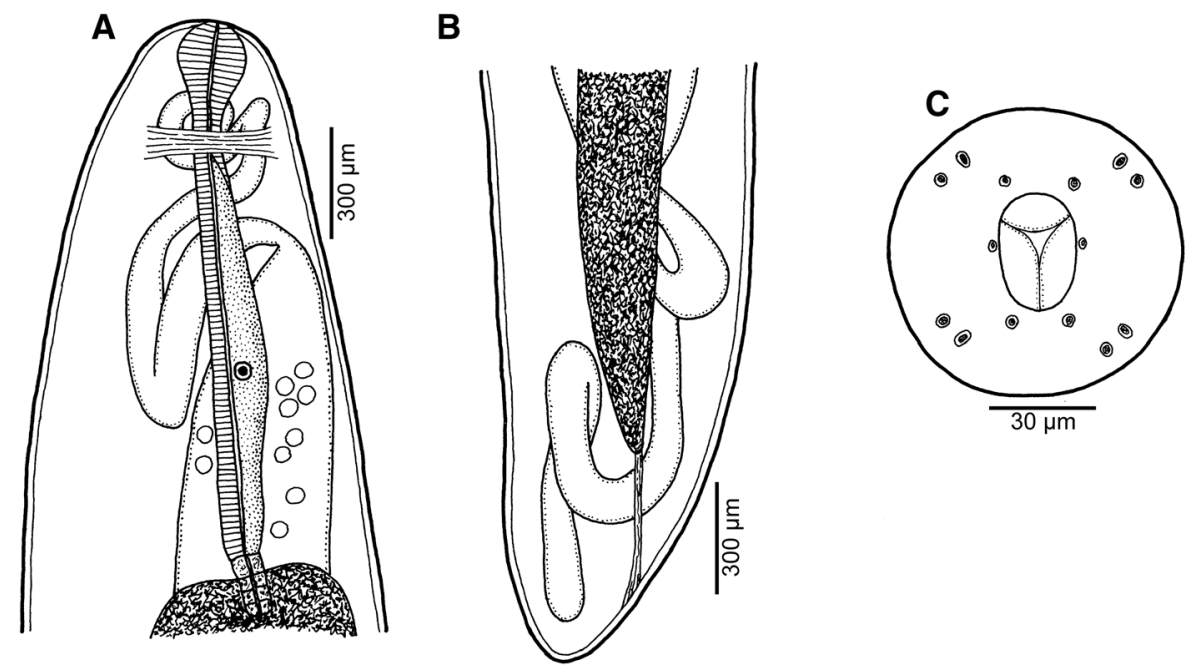

Fig. 4 Philometra sp. from Platycephalus indicus, subgravid female. A, Anterior end, lateral view; B, Posterior end, lateral view; C, Cephalic end, apical view

Of the four above-mentioned species with spicule lengths somewhat similar to those of the new species, only the spicules of $P$. brevicollis are approximately as long as those of $P$. parabrevicollis n. sp. $(279-321 \mu \mathrm{m}$ vs 267-285 $\mu \mathrm{m}$ ), whereas those of $P$. arafurensis, $P$. argentimaculati and $P$. carponotati are somewhat shorter, not exceeding $264 \mu \mathrm{m}$. Also the gubernaculum of $P$. brevicollis is approximately as long as that of the new species (151-168 $\mu \mathrm{m}$ vs 159-168 $\mu \mathrm{m})$, whereas the gubernaculum of $P$. arafurensis, $P$. argentimaculati and $P$. carponotati is shorter, not exceeding 147 $\mu \mathrm{m}$. However, $P$. brevicollis differs from $P$. parabrevicollis $\mathbf{n}$. sp. in the gubernaculum/spicules length ratio (1:1.79-1.93 vs 1.64-1.76), relative length of spicules to the entire body length $(5.0-5.3 \%$ vs 5.5-6.7\%), body length (5.39-5.92 $\mathrm{mm}$ vs 4.03-4.90 $\mathrm{mm}$ ) and in the absence ( $v s$ presence) of a pair of large postcloacal papilla-like protuberances. Philometra brevicollis also differs from the new species in the number (three $v s$ four pairs) of observed adanal papillae, but this is an unrealible feature, because these papillae are usually difficult to observe in philometrids.

Distinction of $P$. parabrevicollis $\mathbf{n}$. sp. from other gonad-infecting species of Philometra parasitising lutjanids is apparent from the key at the end of Discussion.

Philometra sp. 2 of Moravec et al., 2016
Host: Platycephalus indicus (Linnaeus) (Perciformes, Platycephalidae), bartail flathead.

Locality: Near Basrah, northwestern Arabian Gulf, Iraq (collected in February-March 2020).

Voucher specimens: Helminthological Collection of the Institute of Parasitology, BC CAS, České Budějovice, Czech Republic (Cat. No. N-1100).

Prevalence and intensity: 3\% (3fish infected/118 fish examined; 1-4 (mean 2) nematodes per fish.

Site in host: Ovary.

\section{Description}

Subgravid female ([Based on 2 complete and 3 incomplete specimens; Figs. 4A-C, 5A): Body of fixed specimens grey-coloured, 96-195 mm long, maximum width 938-1,251; maximum width/body length ratio 1:102-156. Cephalic end rounded, 258-340 wide. Cephalic papillae very small, indistinct in lateral view (Fig. 4A). Oral aperture oval, surrounded by 14 small cephalic papillae arranged in 2 circles: 4 submedian pairs of papillae of outer circle and 6 single papillae (4 submedian and 2 lateral) of inner circle; amphids indistinct (Figs. 4C, 5A). Oesophagus 1.29-1.56 mm long including its anterior bulbous inflation, representing $0.8-1.3 \%$ of body length; anterior inflation 150-177 long and 177 wide; maximum width of posterior part of oesophagus including well-developed dorsal gland 136-163 (Fig. 4A). Small ventriculus present, 27-68 long, 95 

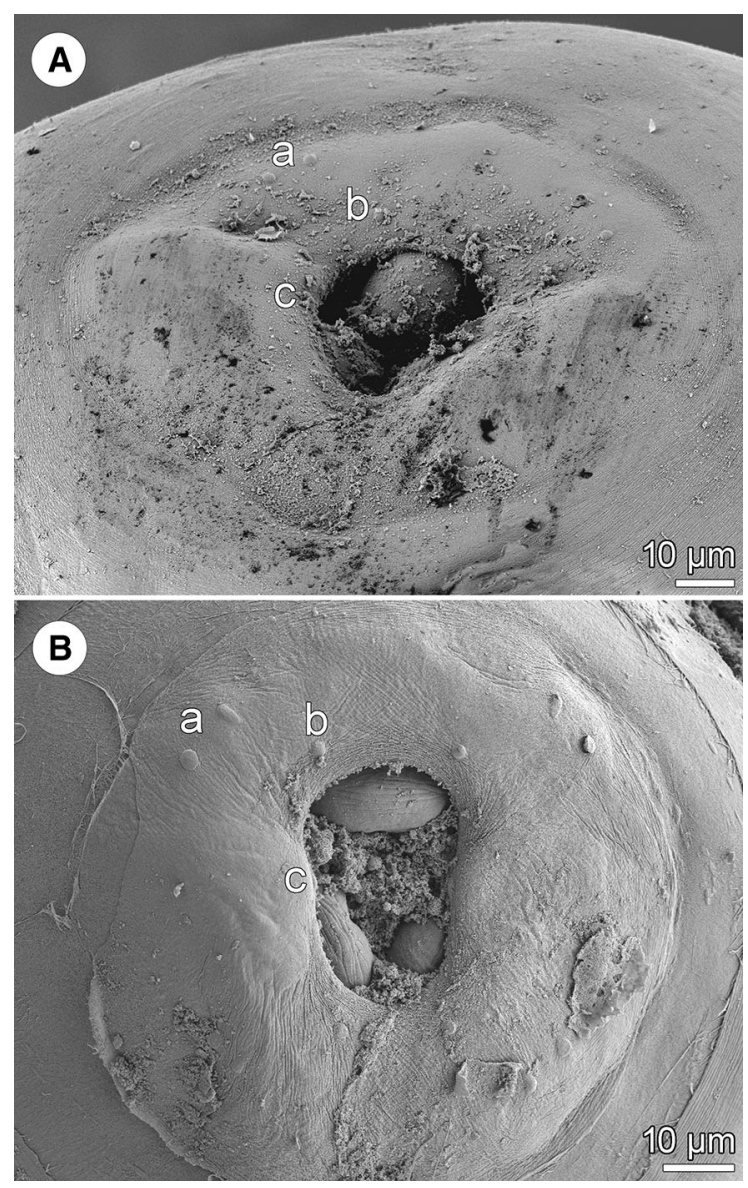

Fig. 5 Philometra sp. from Platycephalus indicus, scanning electron micrographs. A, Cephalic end of subgravid female from Iraq, subapical view; B, Cephalic end of gravid female from India, apical view. Abbreviations: a, submedian pair of outer cephalic papillae; $b$, inner submedian cephalic papilla; $c$, inner lateral cephalic papilla

wide. Nerve-ring and oesophageal nucleus 231-326 and 830-979, respectively, from anterior extremity. Intestine straight, ending blindly; posterior end of intestine atrophied, forming ligament 462-625 long attached ventrally to body wall close to posterior extremity (Fig. 4B). Vulva and anus absent. Ovaries coiled near body ends (Fig. 4A, B). Uterus filled with eggs. Posterior end rounded, 150-190 wide, without caudal projections (Fig. 4B).
Remarks

Two small nongravid and one incomplete (posterior part of body) gravid females from the ovary of $P$. indicus in Iraq were previously described as Philometra sp. 2 by Moravec et al. (2016a). Larger subgravid females of this not yet established species are described in this paper for the first time.

According to Moravec et al. (Moravec et al. 2016a, these nematodes are probably conspecific with those described by Moravec \& Nagasawa (1989) from the gonads of $P$. indicus off Japan and misidentified as Philometra inimici Yamaguti, 1941. In 2013, the senior author (F.M.) of the present paper examined one gravid female of Philometra (Fig. 5B), $92 \mathrm{~mm}$ long, from the ovary of $P$. indicus of the Bay of Bengal, India, sent to him by Dr. Jayaraman Manoharan; this finding has not been published. It is highly probable that all these nematodes from the gonads of $P$. indicus collected in Iraq, India and Japan belong to the same, hitherto undescribed species of Philometra, whose distribution area coincides more or less with the Indian-West Pacific distribution of its host $P$. indicus. Since the female morphology of available specimens is similar to that of most other gonad-infecting congeners, the new species cannot be established until conspecicific males are collected and described.

\section{Discussion}

The present study shows again the importance of male morphology for the taxonomy of philometrids, because females of many species of Philometra are very similar and practically indistinguishable from each other by morphological features. As mentioned by Moravec et al. (2021), besides the shape and lengths of spicules, the most important taxonomic features of these parasites seem to be a detailed structure of the male caudal end and, in particular, the structure of the gubernaculum distal tip. During recent years, especially the latter feature made it possible to distinguish between some gonad-infecting species of Philometra with morphologically indistinguishable females (e.g., Moravec et al., 2016b; Ghanmi et al., 2018; Moravec \& Barton, 2018). However, it is necessary to note that the details of the gubernaculum have to be studied by SEM.

Snappers (Lutjanus spp.) seem to be frequently parasitised by philometrid nematodes (Moravec et al., 
2014). Besides Dentiphilometra lutjani GonzálezSolís, Moravec \& Tuz Paredes, 2007 (a parasite of body musculature) and Philometra brevispicula Moravec a Bakenhaster, 2010 (a parasite of mouth tissues), both parasites of Lutjanus griseus (Linnaeus) in Florida Bay, USA and off the Caribbean coast of Mexico, respectively (González-Solís et al., 2007; Moravec \& Bakenhaster, 2010) and D. malabarici Moravec \& Barton, 2018 and P. papillicaudata Moravec \& Barton, 2018 (both parasites of tissues behind gills) of Lutjanus malabaricus (Bloch et Schneider) and L. sebae (Cuvier), respectively, from off northern Australia (Moravec \& Barton, 2018), all other remaining species are represented by the parasites of fish gonads. The males of all these 11 nominal gonad-infecting species of Philometra (see above) are known and only those of $P$. mira have not yet been studied by SEM.

The present description of an additional new gonadinfecting species of Philometra from L. lutjanus off Iraq confirms the high degree of host specificity of these nematodes previously observed in Lutjanus spp. in the Gulf of Mexico (Moravec et al., 2014), in the Bay of Bengal (Moravec \& Manoharan, 2014b) and in northern Australian waters (Moravec \& Barton, 2018).

\section{Key to gonad-infecting species of Philometra par- asitising fishes of the family Lutjanidae:}

1a Spicules longer than $350 \mu \mathrm{m}$.................. 2

$1 \mathrm{~b}$ Spicules shorter than $350 \mu \mathrm{m}$.................. 3

2a Spicules 459-690 $\mu \mathrm{m}$ and 378-618 $\mu \mathrm{m}$ long; Longer spicule represents $13-19 \%$ of body length. Length ratio of gubernaculum and longer spicule 1:4.5-6.9. Gravid female 130-250 mm long. In Lutjanus campechanus and L. vivanus; Gulf of Mexico P. longispicula

2b Spicules 384-435 $\mu \mathrm{m}$ and 351-420 $\mu \mathrm{m}$ long; longer spicule represents $10-11 \%$ of body length. Length ratio of gubernaculum and longer spicule 1:2.1-2.4. Gravid female 70-111 mm long. In Lutjanus malabaricus; off Australia

P. mawsonae

3a Spicules shorter than $150 \mu \mathrm{m}$................. 4

$3 \mathrm{~b}$ Spicules longer than $150 \mu \mathrm{m}$.................. 6

4a Spicules 96-105 $\mu \mathrm{m}$ long. Length of gubernaculum 78-84 $\mu \mathrm{m}$. Body length of male $3.47-3.66 \mathrm{~mm}$. Female unknown. In Lutjanus vitta; off New Caledonia . P. mira 4b Spicules longer than $120 \mu \mathrm{m}$.................. 5

5a Gubernaculum 69-93 $\mu \mathrm{m}$ long, its distal end with dorsal protuberance (in lateral view) and with numerous dorsal lamela-like structures arranged in 2 longitudinal rows separated by median groove (3 posteriormost lamellae undivided). Spicules 123-138 $\mu \mathrm{m}$ long. Body length of gravid female $230 \mathrm{~mm}$. In Lutjanus fulvus (Lutjanidae); Indian Ocean (Bay of Bengal) P. fulvi

5b Gubernaculum 117-126 $\mu \mathrm{m}$ long, its distal end without dorsal protuberance in lateral view but with dorsal surface forming distinct longitudinal ridge of evenly spaced chevron-shaped serrations. Spicules 135-144 $\mu \mathrm{m}$ long. Gravid female not known (subgravid female up to $90 \mathrm{~mm}$ long). In Lutjanus griseus (Lutjanidae); Gulf of Mexico ............. P. latispicula

6a Body length of male 5.39-5.92 mm. Spicules 279-312 $\mu \mathrm{m}$ long. Length of gubernaculum 151-168 $\mu \mathrm{m}$; length ratio of gubernaculum and spicules 1:1.79-1.93; distal end of gubernaculum with dorsal surface provided with 2 lateral rows of lamela-like structures and smooth longitudinal median field between them. In Lutjanus vitta (Lutjanidae); off New Caledonia ........................... P. brevicollis

$6 \mathrm{~b}$ Body length of male less than $5 \mathrm{~mm}$.......... 7

7a Spicules 267-285 $\mu \mathrm{m}$ long, length of gubernaculum 159-168 $\mu \mathrm{m}$; length ratio of gubernaculum and spicules 1:1.64-1.76; distal end of gubernaculum with dorsal surface provided with 2 lateral rows of lamelalike structures and smooth longitudinal median field between them. Gravid female not known. In Lutjanus lutjanus; off Iraq ............ P. parabrevicollis $\mathbf{n} . \mathbf{s p .}$

$7 \mathrm{~b}$ Spicules at most $264 \mu \mathrm{m}$ long, gubernaculum shorter than $150 \mu \mathrm{m}$............................ 8

8a Gubernaculum 129-147 $\mu \mathrm{m}$ long, its distal end with dorsal protuberance in lateral view and dorsal surface provided with 2 lateral rows of lamela-like structures and smooth median longitudinal field between them. Spicules 252-264 $\mu \mathrm{m}$ long. Gravid female $220 \mathrm{~mm}$ long. In Lutjanus sebae; off northern Australia P. arafurensis

$8 \mathrm{~b}$ Gubernaculum less than $120 \mu \mathrm{m}$ long. Spicules usually shorter ............................... 9

9a Spicules 225-252 $\mu \mathrm{m}$ long. Length of gubernaculum 99-117 $\mu \mathrm{m}$. Gravid female $72 \mathrm{~mm}$ long. In Lutjanus carponotatus; off northern Australia ... ..P. carponotati

$9 \mathrm{~b}$ Spicules usually shorter.................... 10 
10a Spicules 180-219 $\mu \mathrm{m}$ long, representing 4-5\% of body length. Length of gubernaculum 69-90 $\mu \mathrm{m}$. Gravid female $152 \mathrm{~mm}$ long. In Lutjanus synagris; Gulf of Mexico .......................... P. synagridis

10b Spicules 219-228 $\mu \mathrm{m}$ long, representing 7-9\% of body length. Length of gubernaculum 90-120 $\mu \mathrm{m}$. Gravid females 164-300 mm long. In Lutjanus argentimaculatus; Indian Ocean (Bay of Bengal) P. argentimaculati

Acknowledgements We thank the Department of Fisheries and Marine Resources, College of Agriculture, University of Basrah for support specially during Covid-19 pandemic. Thanks are also due to the Laboratory of Electron Microscopy, Institute of Parasitology, Biology Centre CAS, institution supported by the MEYS CR (LM2015062 Czech-BioImaging) and ERDF (No. CZ.02.1.01/0.0/0.0/16_013/0001775), for their support with obtaining scientific data presented in this paper, and to Blanka Škoríková of the same Institute for help with the illustrations.

Funding This study was partly supported by the institutional support of the Institute of Parasitology, BC AS CR (RVO: 60077344).

\section{Compliance with ethical standards}

Conflict of interest The authors declare that they have no conflict of interest.

Ethical approval All applicable institutional, national and international guidelines for the care and use of animals were followed.

\section{References}

Ali, A. H., Mhaisen, F. T., \& Khamees, N. R. (2014). Checklists of nematodes of freshwater and marine fishes of Basrah Province, Iraq. Mesopotamian Journal of Marine Sciences, 29, 71-96.

Al-Jahdali, M. O. (2014). A pathological case caused by Philometra madai Quiazon, Yoshinaga \& Ogawa, 2008 (Nematoda: Philometridae) in the ovary of the onespot snapper fish Lutjanus monostigma (Teleostei, Lutjanidae) from the Red Sea. Journal of Advances in Biology, 6, 843-847.

Anderson, R. C., Chabaud, A. G., \& Willmott, S. (Eds.). (2009). Keys to the nematode parasites of vertebrates (p. 463). CABI: Archival Volume. Wallingford.

Bush, A. O., Lafferty, K. D., Lotz, J. M., Shostak, A. W., et al. (1997). Parasitology meets ecology on its own terms: Margolis et al. revisited. Journal of Parasitology, 83, $575-583$.

El-Naffar, M. K. I., Gobashy, A., El-Etreby, S. G., \& Kardousha, M. M. (1992). General survey of helminth parasite genera of Arabian Gulf fishes (coasts of United Arab Emirates).
Arab Gulf Journal of Scientific Research, Riyadh, 10, 99-110.

Froese, R., \& Pauly, D. (Eds) (2021). FishBase. World Wide Web electronic publication, http://www.fishbase.org, version $03 / 2021$.

Ghanmi, N., González-Solís, D., \& Gargouri, L. (2018). Two new gonad-infecting species of Philometra (Nematoda: Philometridae) from Trachinus spp. (Osteichthyes: Trachinidae) in the Gulf of Hammamet. Tunisia. Systematic Parasitology, 95, 223-234.

González-Solís, D., Moravec, F., \& Tuz Paredes, V. M. (2007). A new species of Dentiphilometra (Nematoda: Philometridae) from the musculature of the gray snapper Lutjanus griseus (Osteichthyes) off the Caribbean coast of Mexico. Journal of Parasitology, 93, 1132-1135.

Hosseini, S. H., Alinezhad, S., Mobedi, I., Halajian, A., Karimi, E., Ahoo, M. B., et al. (2013). Study on the parasites of Pseudorhombus elevatus, Psettodes erumei and Brachirus orientalis from the Persian Gulf. Iran. Iranian Journal of Fiesheries Sciences, 12, 827-835.

Ivashkin, V. M., Sobolev, A. A., \& Khromova, L. A. (1971). Camallanata of animals and man and the diseases caused by them. Osnovy Nematodologii 22. Moscow: Nauka, 388 pp. (In Russian).

Kardousha, M. M. (1999). The first record of Philometra lateolabracis Yamaguti, 1935 (Nematoda: Spirurida; Philometridae) from teleost fishes of the Arabian Gulf. Qatar University Science Journal, 18, 131-136. (In Arabic, English abstract).

Mohamed, A. H., Hassan, M. A., \& Mahmoud, M. A. (2010). Infestation of some marine fish species with red worm Philometra. Arab Gulf Journal of Scientific Research, 28, 137-146.

Moravec, F. (2006). Dracunculoid and anguillicoloid nematodes parasitic in vertebrates (p. 634). Prague: Academia.

Moravec, F., \& Ali, A. H. (2005). Two new species of Philometra (Nematoda: Philometridae) from needlefishes (Belonidae) in Iraq, with a key to Philometra spp. parasitic in the host's subcutaneous tissues, fins and musculature. Folia Parasitologica, 52, 267-273.

Moravec, F., \& Ali, A. H. (2013). Philometra johnii sp. nov. (Nematoda, Philometridae), a new gonad-infecting philometrid from the sin croaker Johnius dussumieri (Cuvier) (Perciformes, Sciaenidae) from marine waters of Iraq. Acta Parasitologica, 58, 263-268.

Moravec, F., \& Ali, A. H. (2014). Additional observations on Philometra spp. (Nematoda: Philometridae) in marine fishes off Iraq, with the description of two new species. Systematic Parasitology, 87, 259-271.

Moravec, F., Ali, A. H., Abed, J. M., \& Shaker, S. J. (2016a). New records of philometrids (Nematoda: Philometridae) from marine fishes off Iraq, with the erection of two new species and the first description of the male of Philometroides eleutheronemae Moravec \& Manoharan, 2013. Systematic Parasitology, 93, 129-144.

Moravec, F., \& Barton, D. P. (2018). New records of philometrids (Nematoda: Philometridae) from marine fishes off Australia, including description of four new species and erection of Digitiphilometroides gen. n. Folia Parasitologica, 65, 005. 
Moravec, F., Barton, D. P., \& Shamsi, S. (2021). Two species of philometrid nematodes (Philometridae) newly recorded from marine fishes off South Australia, including Philometra inconveniens n. sp. from Hyporhamphus melanochir (Valenciennes) (Hemiramphidae). Systematic Parasitology. https://doi.org/10.1007/s11230-021-099860 .

Moravec, F., \& Bakenhaster, M. (2010). Philometrid nematodes infecting fishes from the Everglades National Park, Florida, USA, with description of two new species. Folia Parasitologica, 57, 213-222.

Moravec, F., Bakenhaster, M., \& Fajer-Ávila, E. J. (2014). Three new gonad-infecting species of Philometra (Nematoda: Philometridae) parasitic in Lutjanus spp. (Lutjanidae) in the northern Gulf of Mexico off Florida, USA. Folia Parasitologica, 61, 355-369.

Moravec, F., Chaabane, A., Neifar, L., Gey, D., \& Justine, J.-L. (2016b). Descriptions of Philometra aenei n. sp. and P. tunisiensis n. sp. (Nematoda: Philometridae) from Epinephelus spp. off Tunisia confirm a high degree of host specificity of gonad-infecting species of Philometra Costa, 1845 in groupers (Serranidae). Systematic Parasitology, 93, 115-128.

Moravec, F., \& de Buron, I. (2013). A synthesis of our current knowledge of philometrid nematodes, a group of increasingly important fish parasites. Folia Parasitologica, 60, 81-101.

Moravec, F., \& Diggles, B. K. (2014). Two new gonad-infecting species of Philometra Costa, 1845 (Nematoda: Philometridae) from marine fishes off the northern coast of Australia. Systematic Parasitology, 89, 33-44.

Moravec, F., Jassim, A. A. R., \& Al-Salim, N. K. (2012). Philometroides acanthopagri sp. nov., a new philometrid (Nematoda, Philometridae) from the musculature of Acanthopagrus latus (Sparidae) from marine waters of Iraq. Acta Parasitologica, 57, 372-377.

Moravec, F., \& Justine, J.-L. (2011). Two new gonad-infecting Philometra species (Nematoda: Philometridae) from the marine fish Lutjanus vitta (Perciformes: Lutjanidae) off New Caledonia. Folia Parasitologica, 58, 302-310.

Moravec, F., Khosheghbal, M., \& Pazooki, J. (2013). Two philometrids (Nematoda: Philometridae) infecting the tigertooth croaker Otolithes ruber (Bloch \& Schneider) (Teleostei: Sciaenidae) off Iran, including erection of a new genus. Systematic Parasitology, 86, 33-41.
Moravec, F., \& Manoharan, J. (2014a). Gonad-infecting species of Philometra (Nematoda: Philometridae) from groupers Epinephelus spp. (Osteichthyes: Serranidae) in the Bay of Bengal. India. Acta Parasitologica, 59, 596-605.

Moravec, F., \& Manoharan, J. (2014b). Two new gonad-infecting species of Philometra (Nematoda: Philometridae) parasitic in Lutjanus spp. (Osteichthyes: Lutjanidae) in the Bay of Bengal. India. Parasitology Research, 113, 3299-3307.

Moravec, F., \& Nagasawa, K. (1989). Three species of philometrid nematodes from fishes in Japan. Folia Parasitologica, 36, 143-151.

Moravec, F., Nagasawa, K., Nitta, M., \& Tawa, A. (2019). New records of philometrids (Nematoda: Philometridae) from marine fishes off Japan, including description of Philometra kidakoi sp. n. and Congerinema japonicum gen. et sp. n. Folia Parasitologica, 66, 021.

Moravec, F., \& Shamsi, S. (2017). Barracudia australiensis n. g., n. sp. (Nematoda: Philometridae) from the obtuse barracuda Sphyraena obtusata Cuvier (Perciformes: Sphyraenidae) off eastern Australia. Systematic Parasitology, 94, 627-634.

Parukhin, A. M. (1976). Parasitic worms of commercial fishes of the southern seas. Kiev: Naukova Dumka, 183 pp. (In Russian).

Petter, A.-J., \& Sey, O. (1997). Nematode parasites of marine fishes from Kuwait, with a description of Cucullanus trachinoti n. sp. from Trachinotus blochi. Zoosystema, 19, 35-59.

Quiazon, K. M. A., Yoshinaga, T., \& Ogawa, K. (2008). Taxonomical study into two new species of Philometra (Nematoda: Philometridae) previously identified as Philometra lateolabracis (Yamaguti, 1935). Folia Parasitologica, 55, 29-41.

Van der Laan, R., Fricke, R., \& Eschmeyer, W. N. (Eds) (2021). Eschmeyer's catalog of fishes: classification. Electronic version, http://www.calacademy.org/scientists/catalog-offishes-classification/. Accessed 1st February 2021.

Publisher's Note Springer Nature remains neutral with regard to jurisdictional claims in published maps and institutional affiliations. 